le portiQue $\begin{array}{ll}\text { Le Portique } \\ \text { Revue de philosophie et de sciences humaines }\end{array}$

33 | 2014

Straub !

\title{
Portfolio (2)
}

Philippe Carta, Julien Goetz, Francis Guermann, Bernard Muscat and Michel Noirez

\section{(2) OpenEdition \\ Journals}

Electronic version

URL: http://journals.openedition.org/leportique/2789

DOI: 10.4000/leportique.2789

ISSN: $1777-5280$

\section{Publisher}

Association "Les Amis du Portique"

Printed version

Date of publication: 1 May 2014

ISSN: 1283-8594

\section{Electronic reference}

Philippe Carta, Julien Goetz, Francis Guermann, Bernard Muscat and Michel Noirez, "Portfolio (2)", Le Portique [Online], 33 | 2014, document 2, Online since 14 May 2014, connection on 12 April 2021. URL: http://journals.openedition.org/leportique/2789 ; DOI: https://doi.org/10.4000/leportique.2789

This text was automatically generated on 12 April 2021.

Tous droits réservés 


\section{Portfolio (2)}

Philippe Carta, Julien Goetz, Francis Guermann, Bernard Muscat and Michel Noirez

1 Les photos de ce portfolio ont été prises par Philippe Carta, Julien Goetz, Francis Guermann, Bernard Muscat et Michel Noirez. (Tous droits réservés)

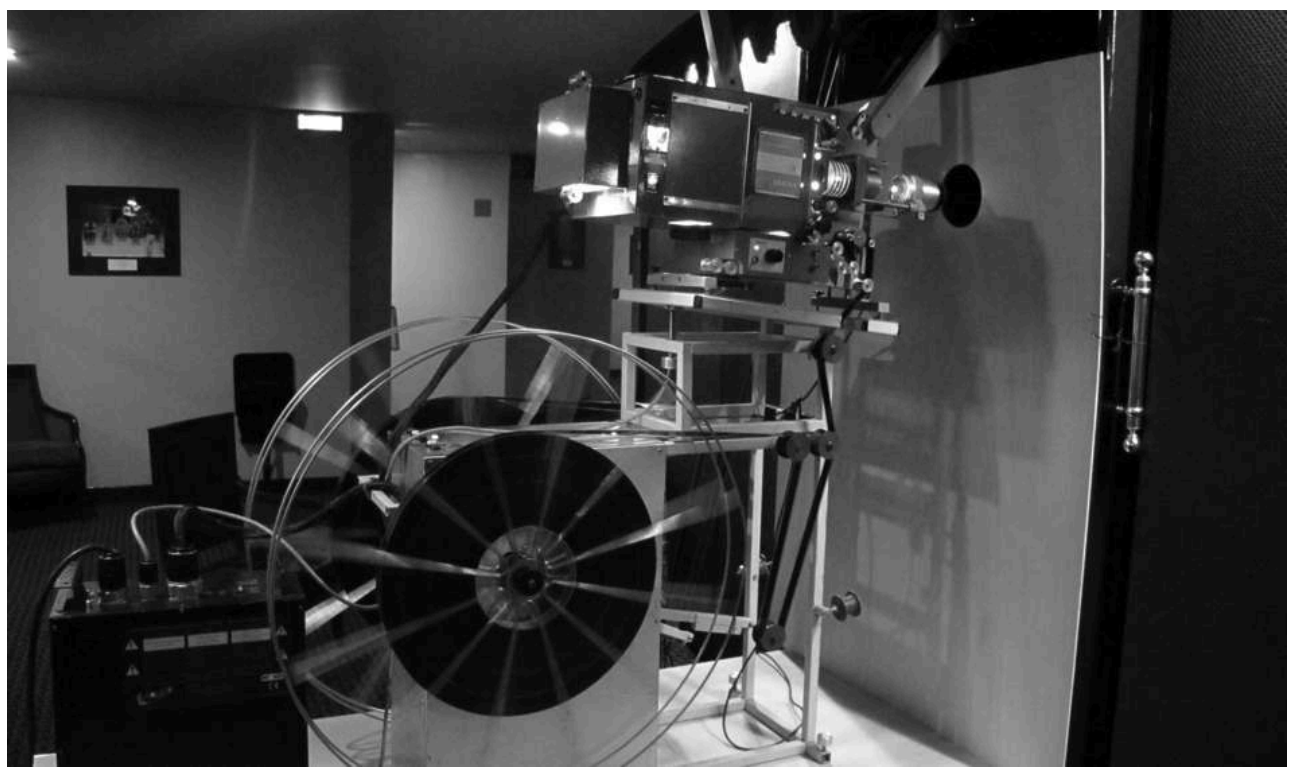

Projecteur et enrouleur 35 mm mobiles installés dans le vestibule de l'Opéra-Théâtre pour la projection de Moïse et Aaron - 24 mars 2011. 


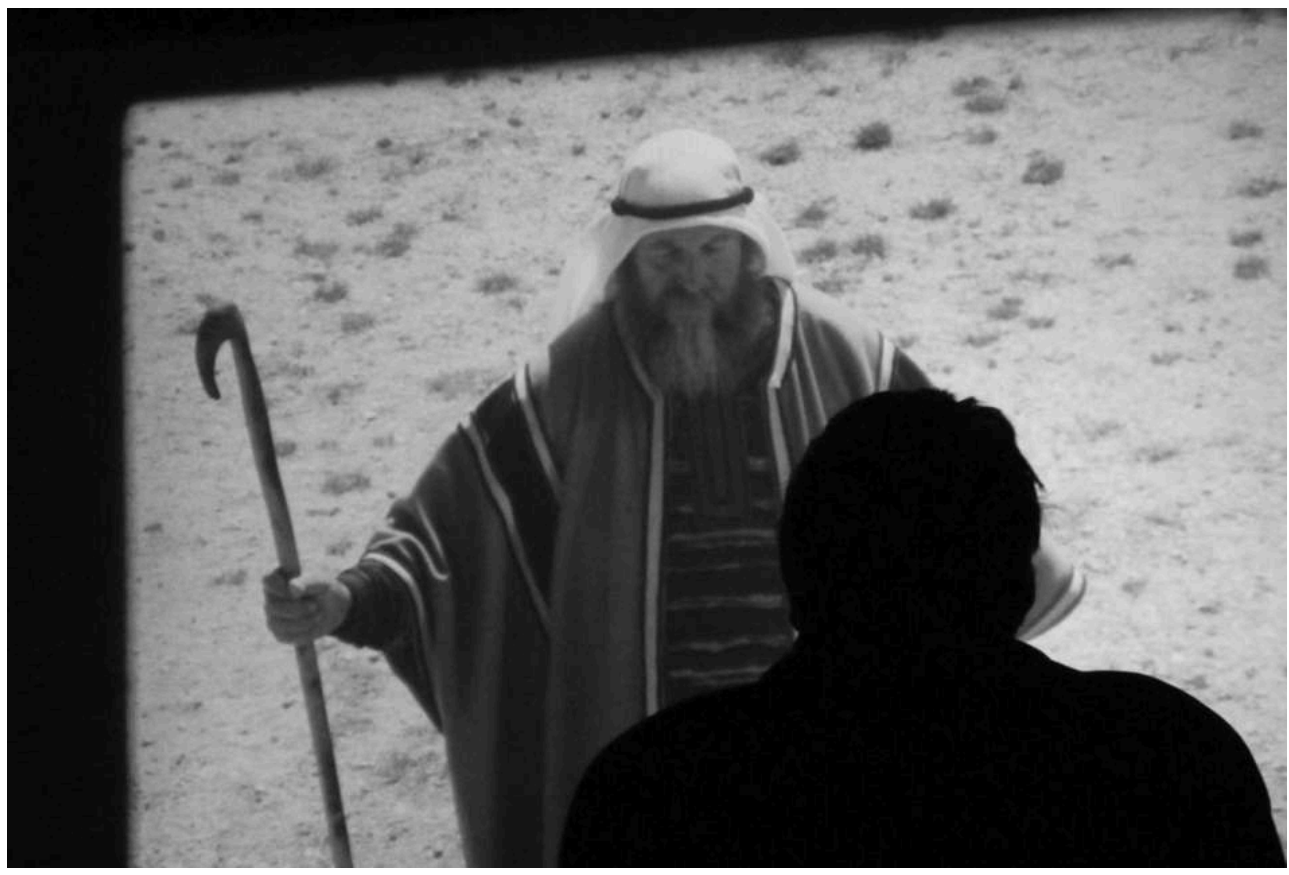

Avant la projection de Moïse et Aaron, Jean-Marie Straub, debout face à l'écran de l'Opéra-Théâtre, vérifie la qualité de l'image et du son.

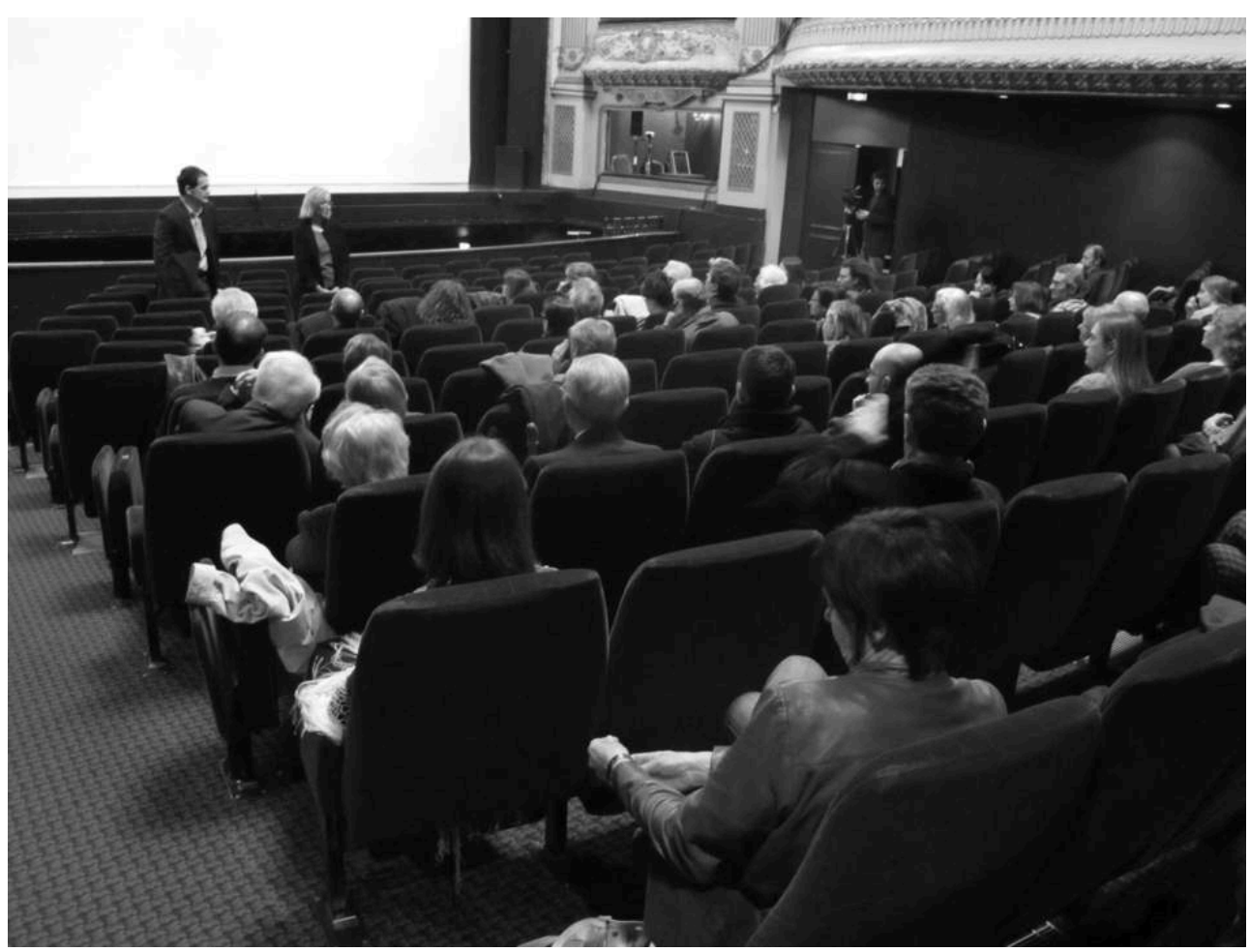

François Narboni et Régine Palucci présentent Moïse et Aaron. 


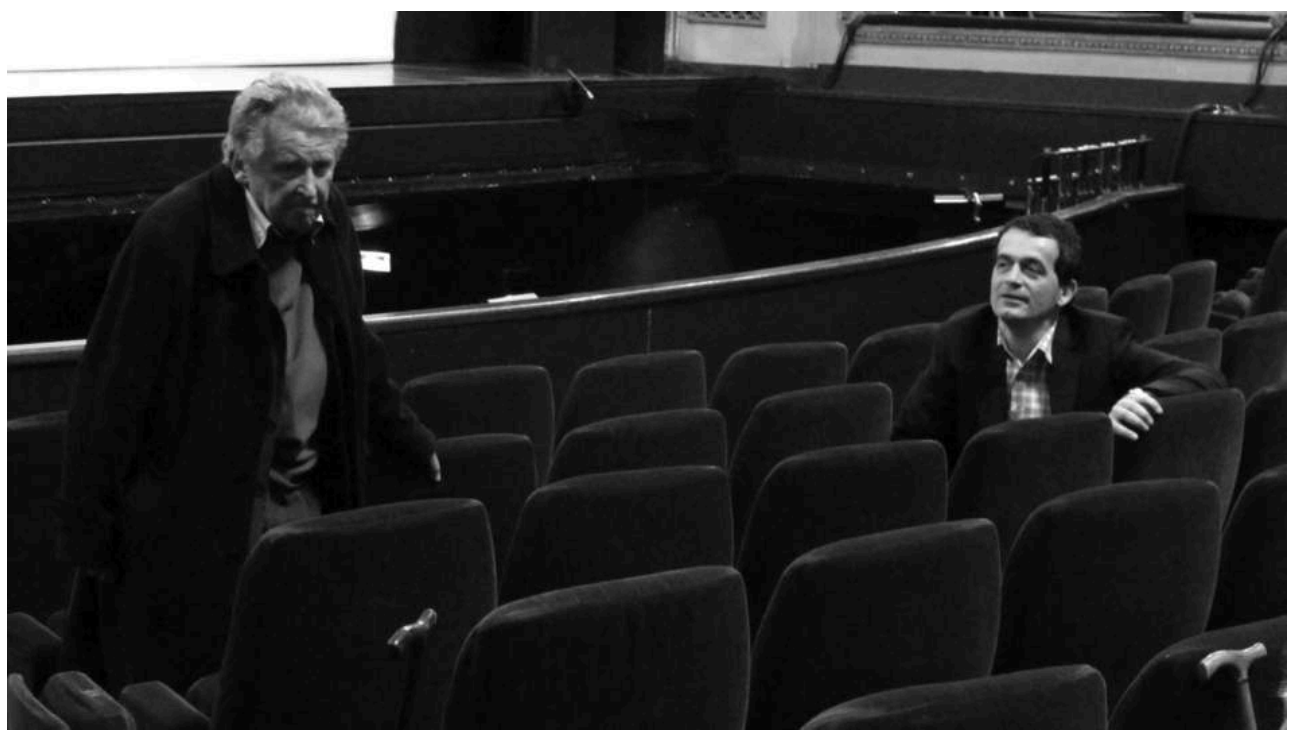

Après la séance, Jean-Marie Straub et François Narboni parlent du film.

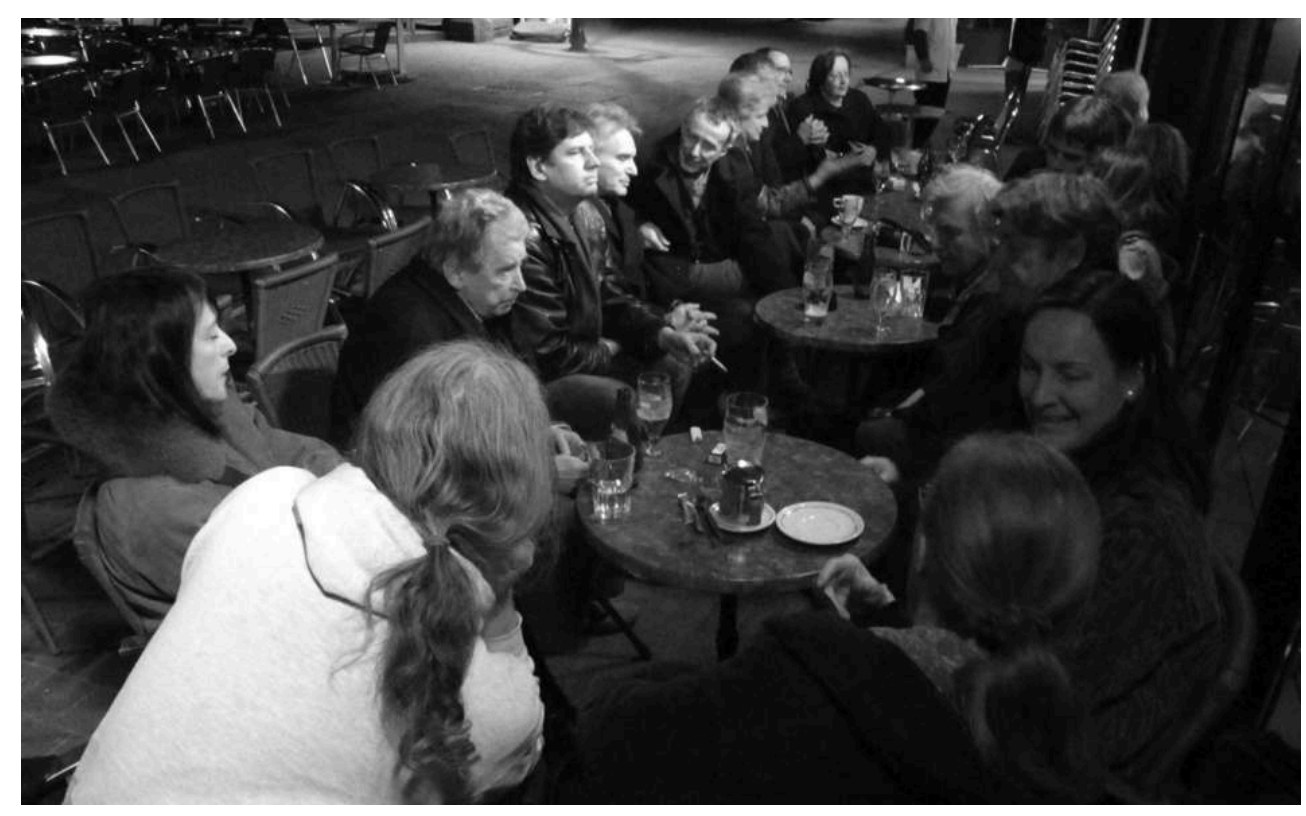

Après la projection, au Caméo, du Caporal épinglé de Jean Renoir, Jean-Marie Straub, entouré de spectateurs et d'amis, prend un verre à une terrasse de la Place Saint-Jacques - 22 mars 2011. 


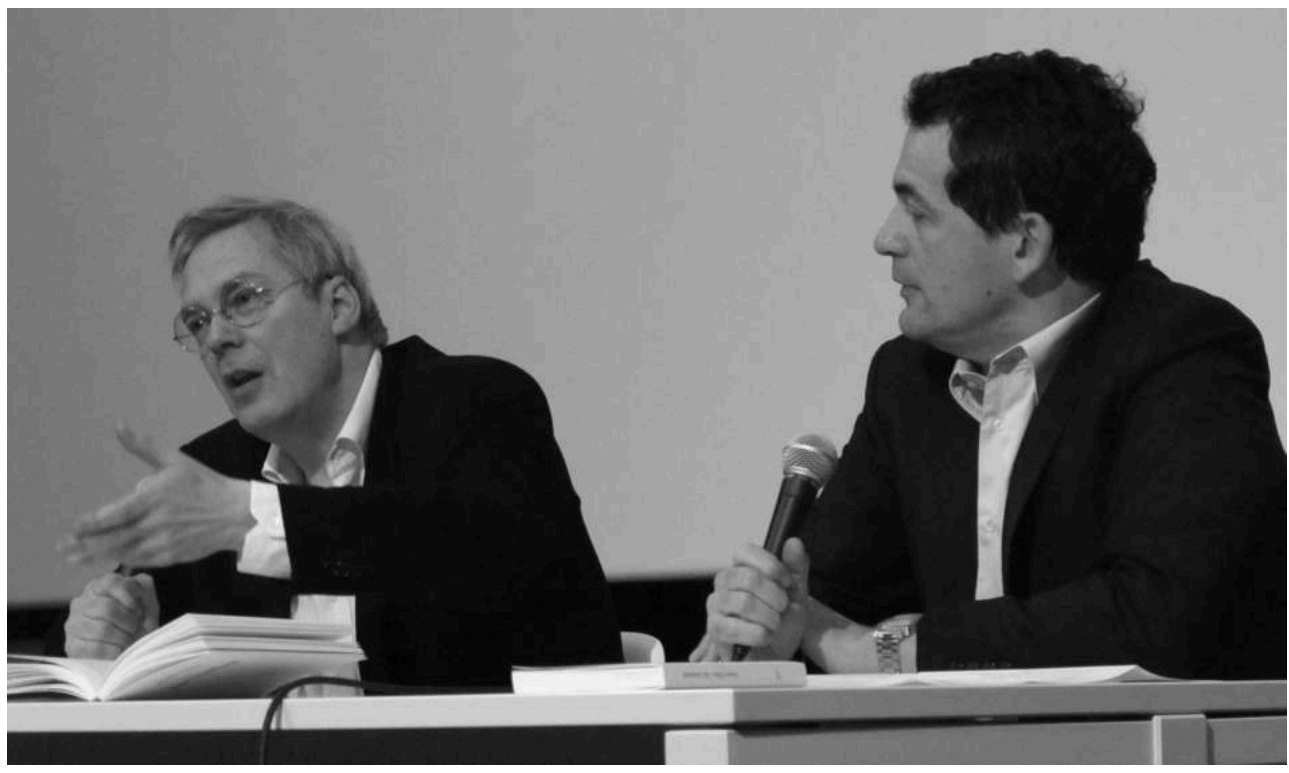

Après Chronique d'Anna Magdalena Bach, rencontre avec Jacques Drillon et François Narboni - 25 mars 2011.

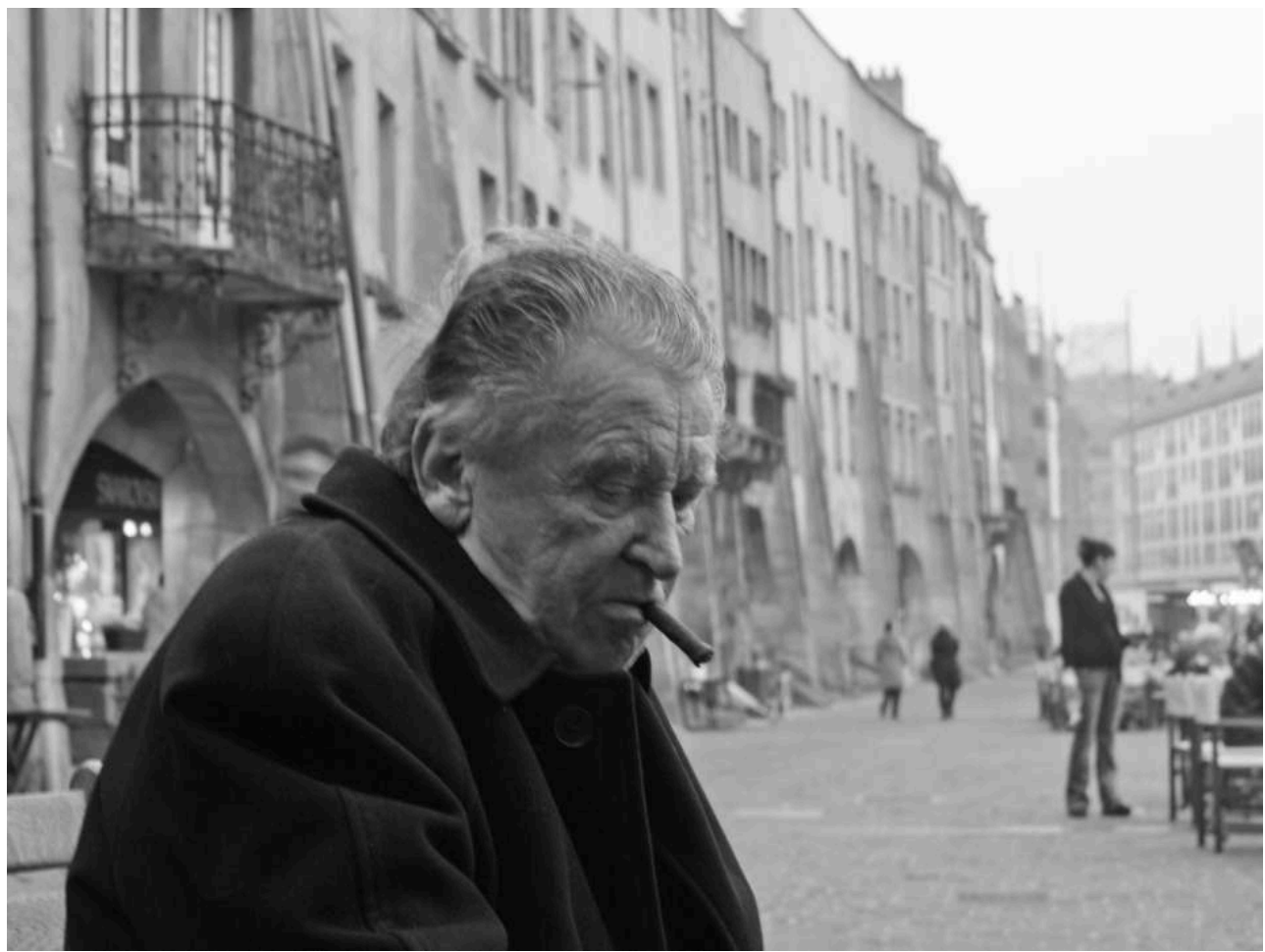

Jean-Marie Straub, place Saint-Louis à Metz - 26 mars 2011. 


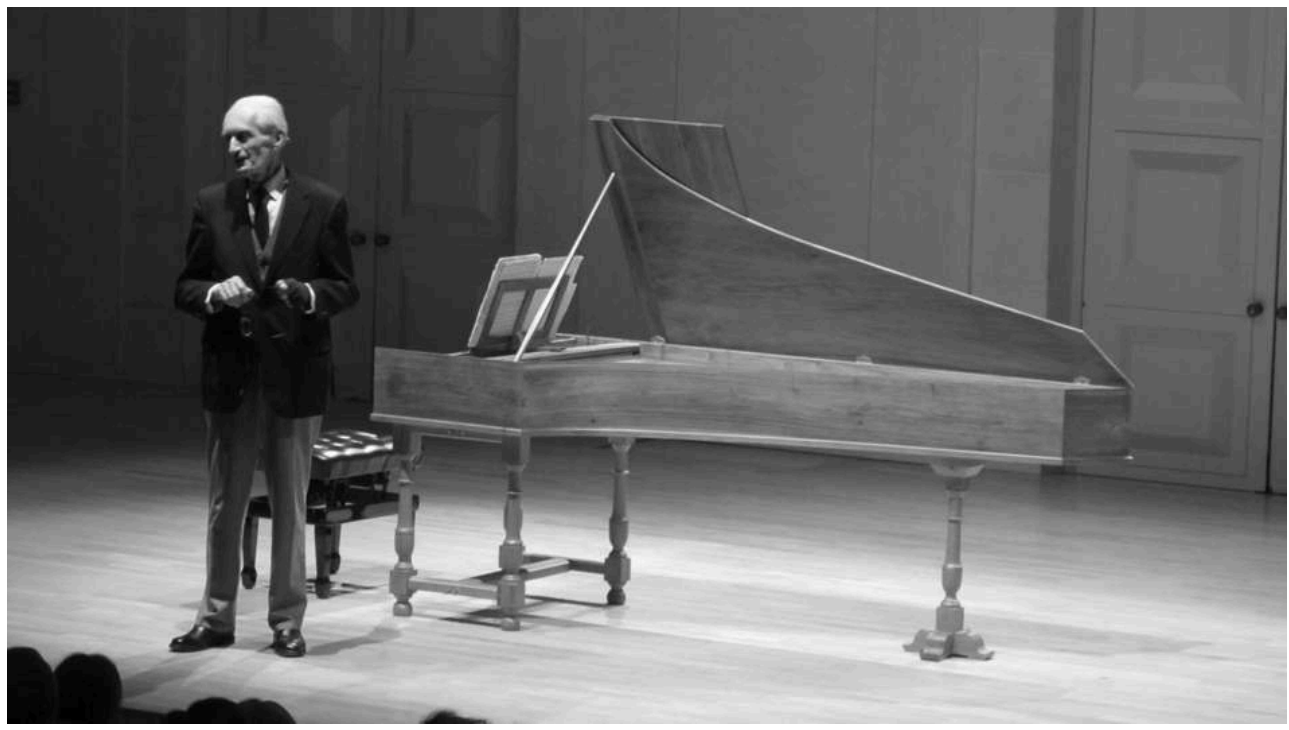

Concert de Gustav Leonhardt à l'Arsenal de Metz - 26 mars 2011.

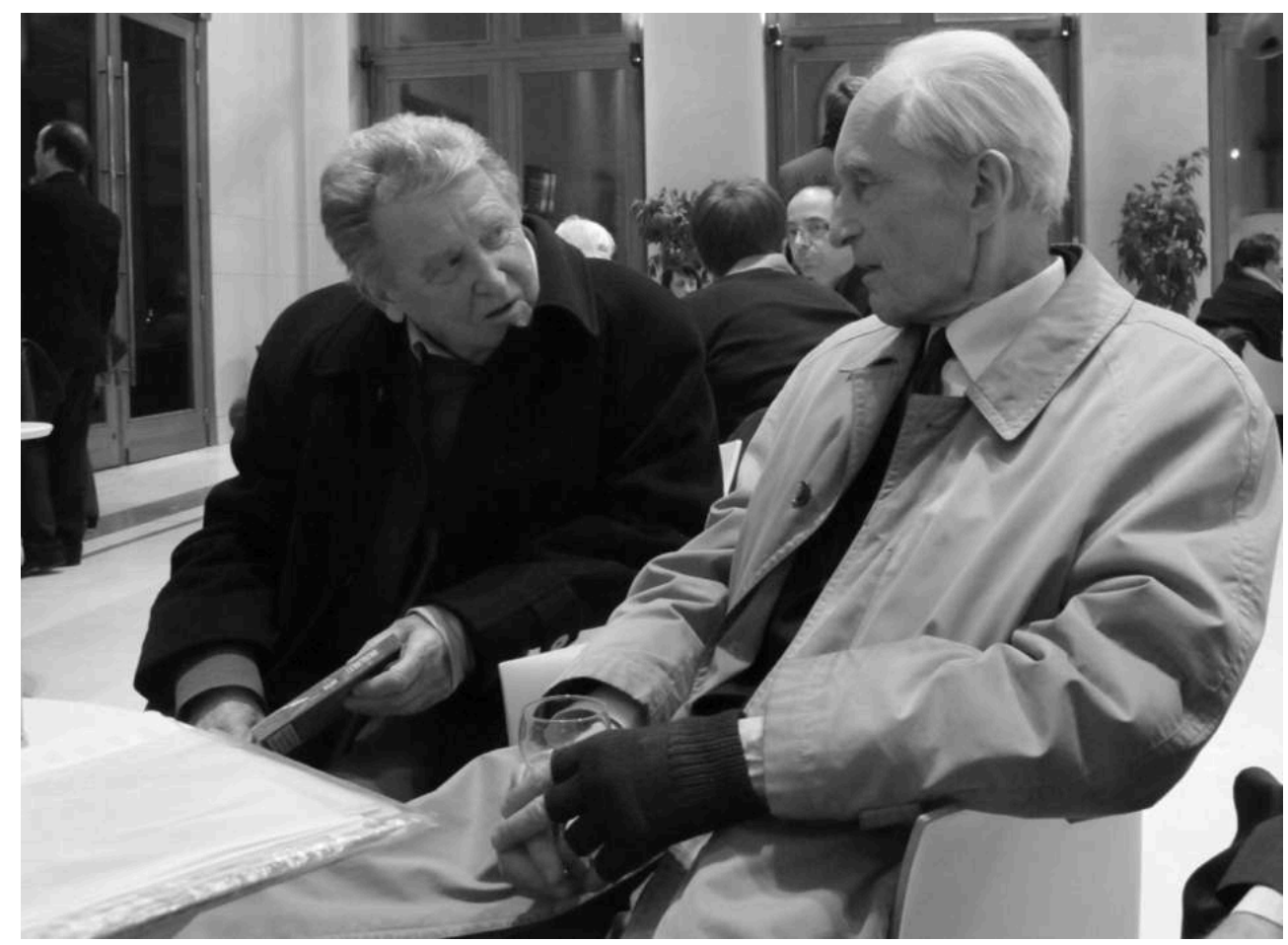

Jean-Marie Straub et Gustav Leonhardt se retrouvent après le concert. 


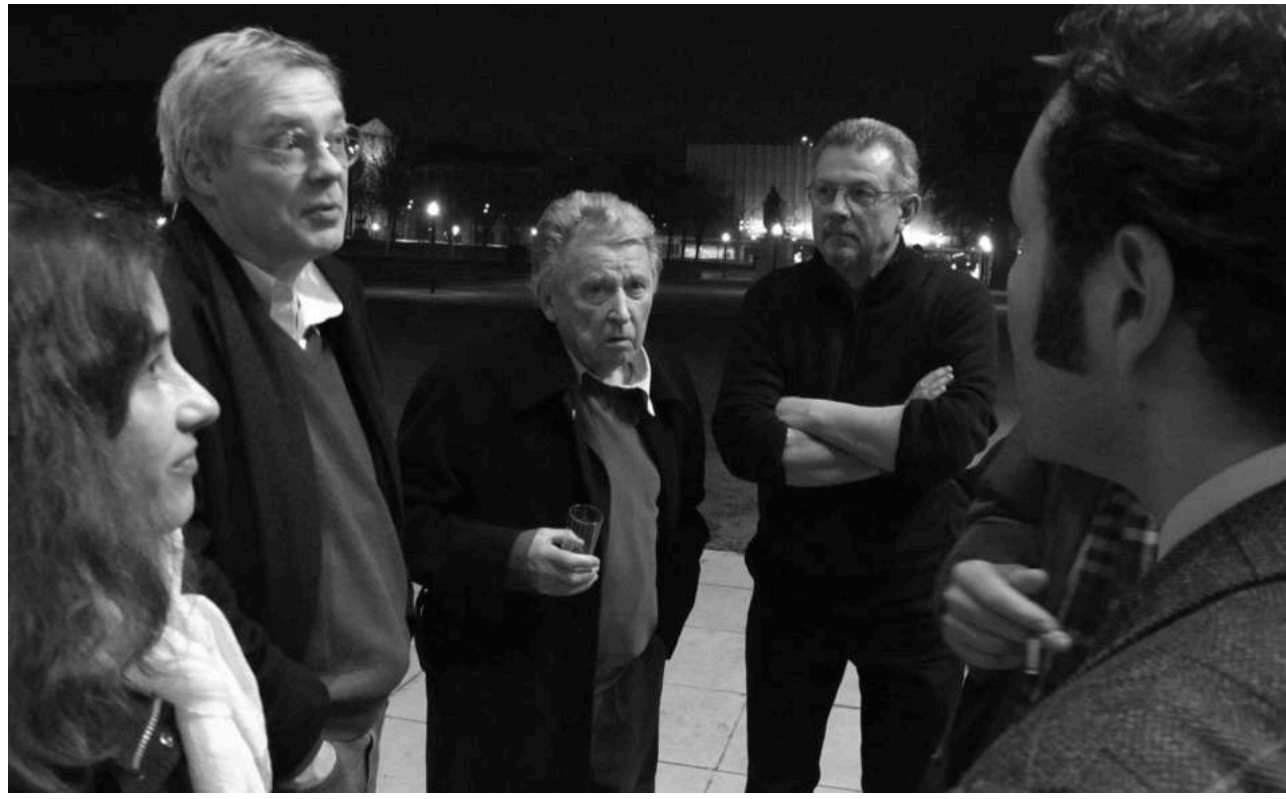

À la sortie du concert, sur l'Esplanade : Jacques Drillon, Jean-Marie Straub, Michel Noirez, Leon Garcia Jordan.

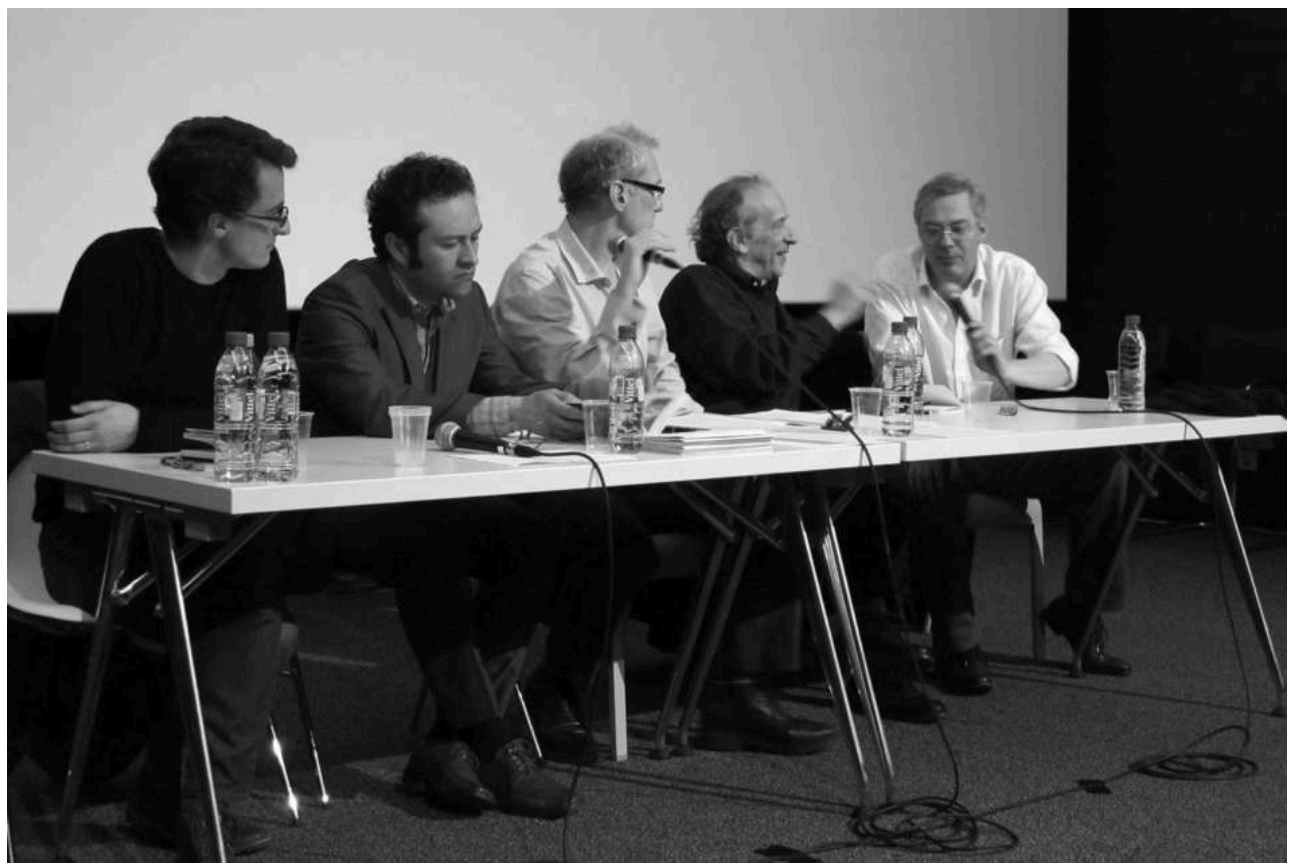

Benoit Turquety, Leon Garcia Jordan, Philippe Lafosse, Renato Berta et Jacques Drillon lors du débat «Sons et images »- 27 mars 2011. 


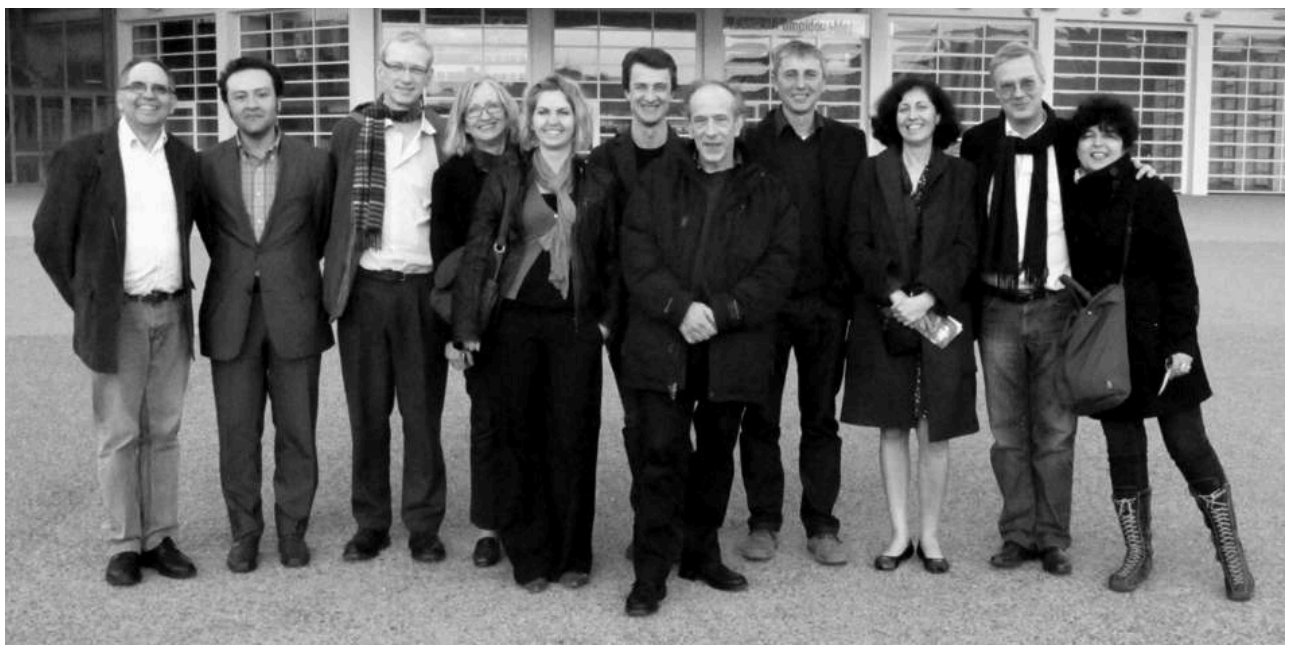

Bernard Muscat, Leon Garcia Jordan, Philippe Lafosse, Régine Palucci, Éloïse Grosjean, Benoît Turquety, Renato Berta, Francis Guermann, Catherine Simon, Jacques Drillon et Dominique Carta, à la sortie du débat «Sons et images »- 27 mars 2011.

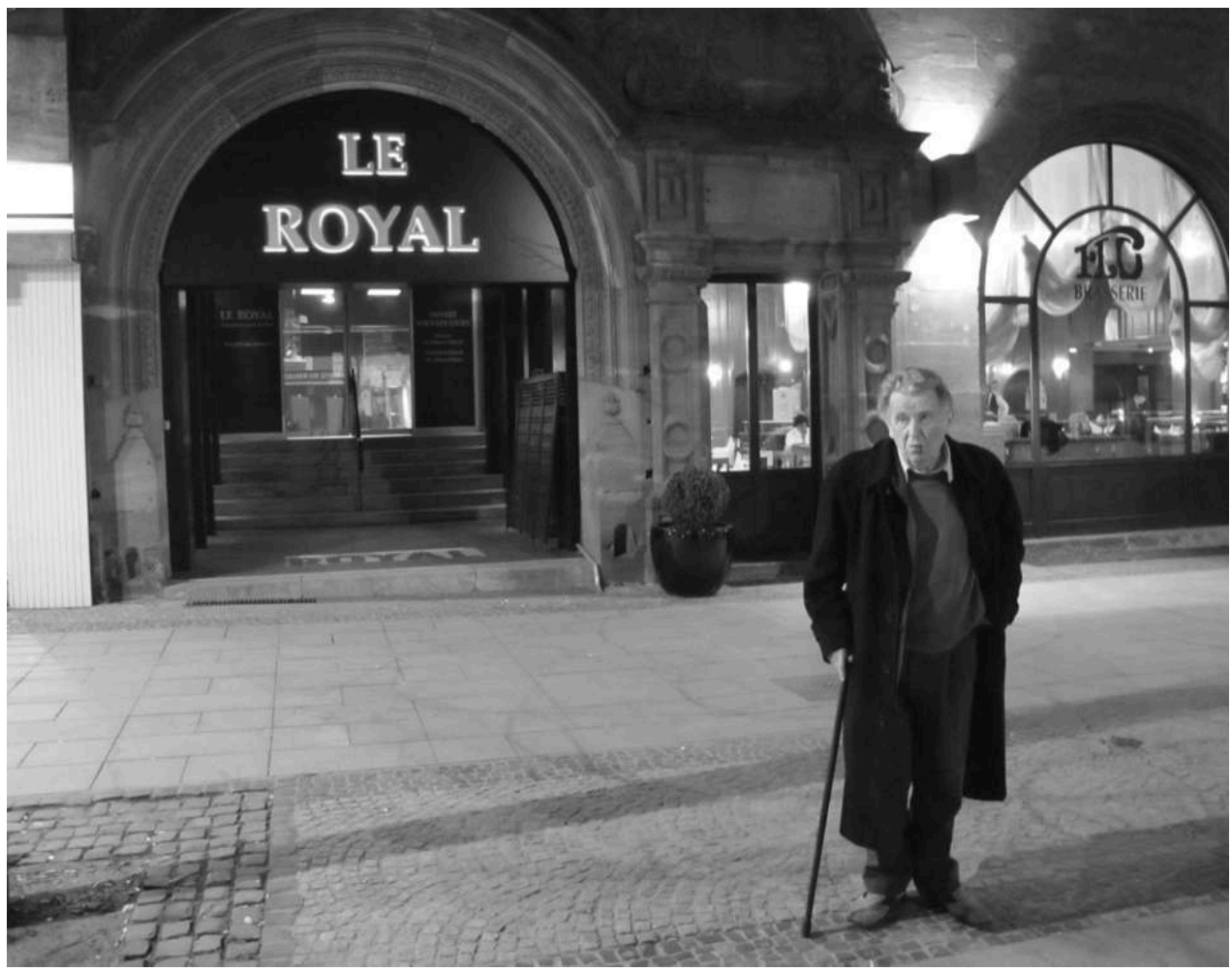

27 mars 2011 - Le cinéma Le Royal, rue Gambetta, dans lequel avaient lieu dans les années cinquante des séances de différents ciné-clubs messins dont La Chambre Noire. C'est là que JeanMarie Straub et ses amis ont fait venir François Truffaut, André Bazin, Jacques Doniol-Valcroze, Henri Agel.. 


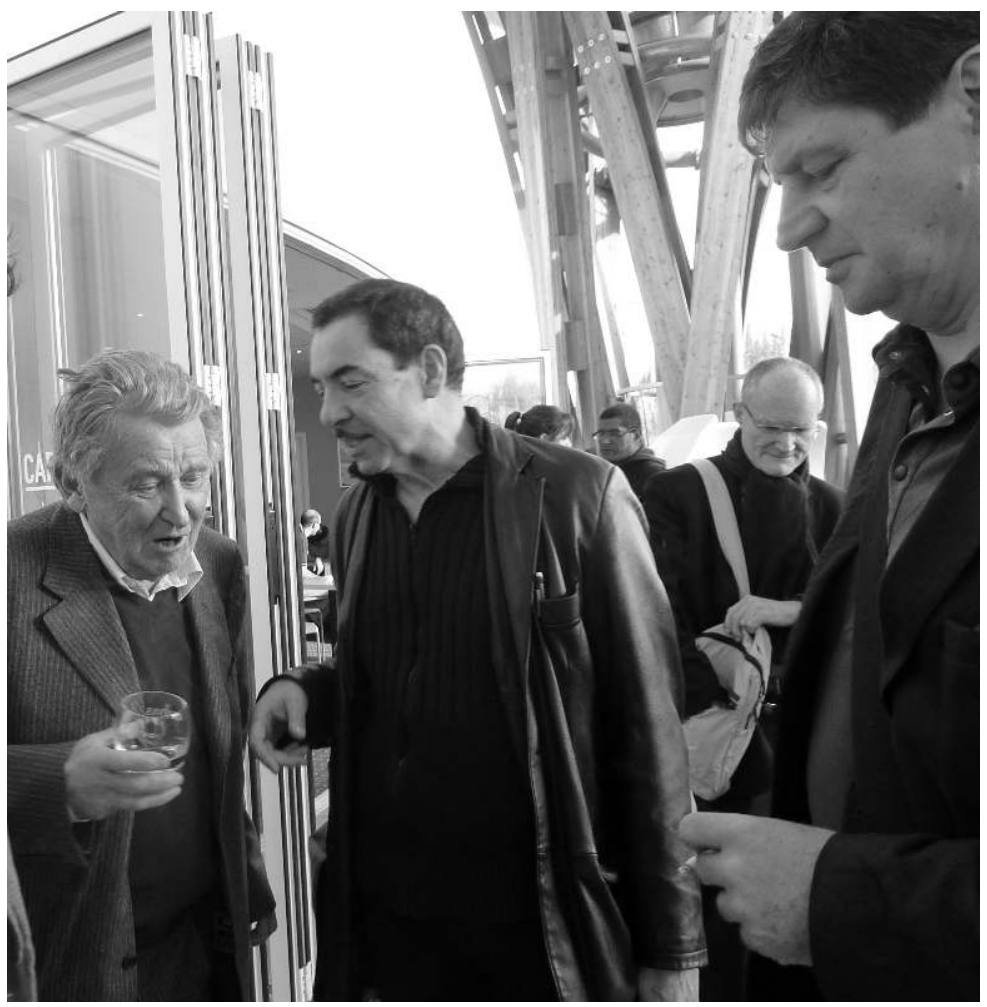

Après le débat « Modernes/Classiques » : Jean-Marie Straub, Jean-Marc Leveratto et Olivier Goetz - 2 avril 2011.

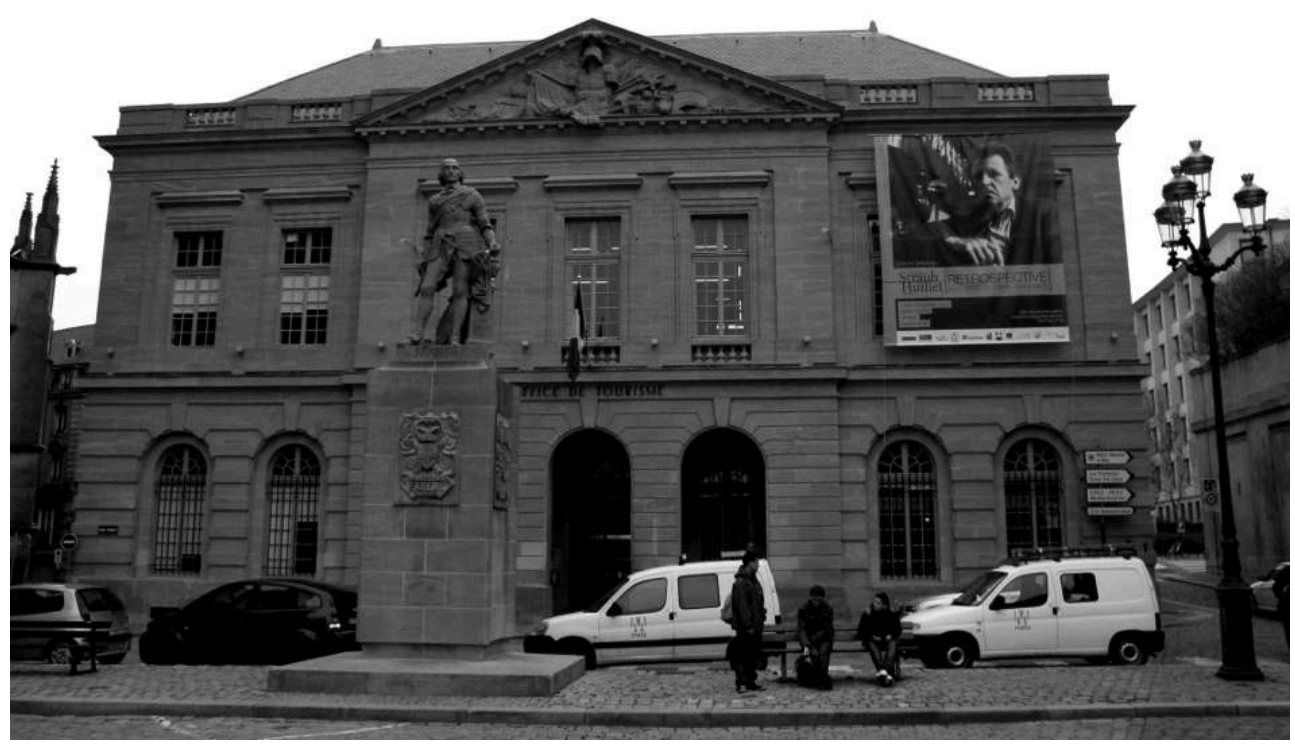

Place d'Armes, l'annonce de la rétrospective Straub-Huillet. 


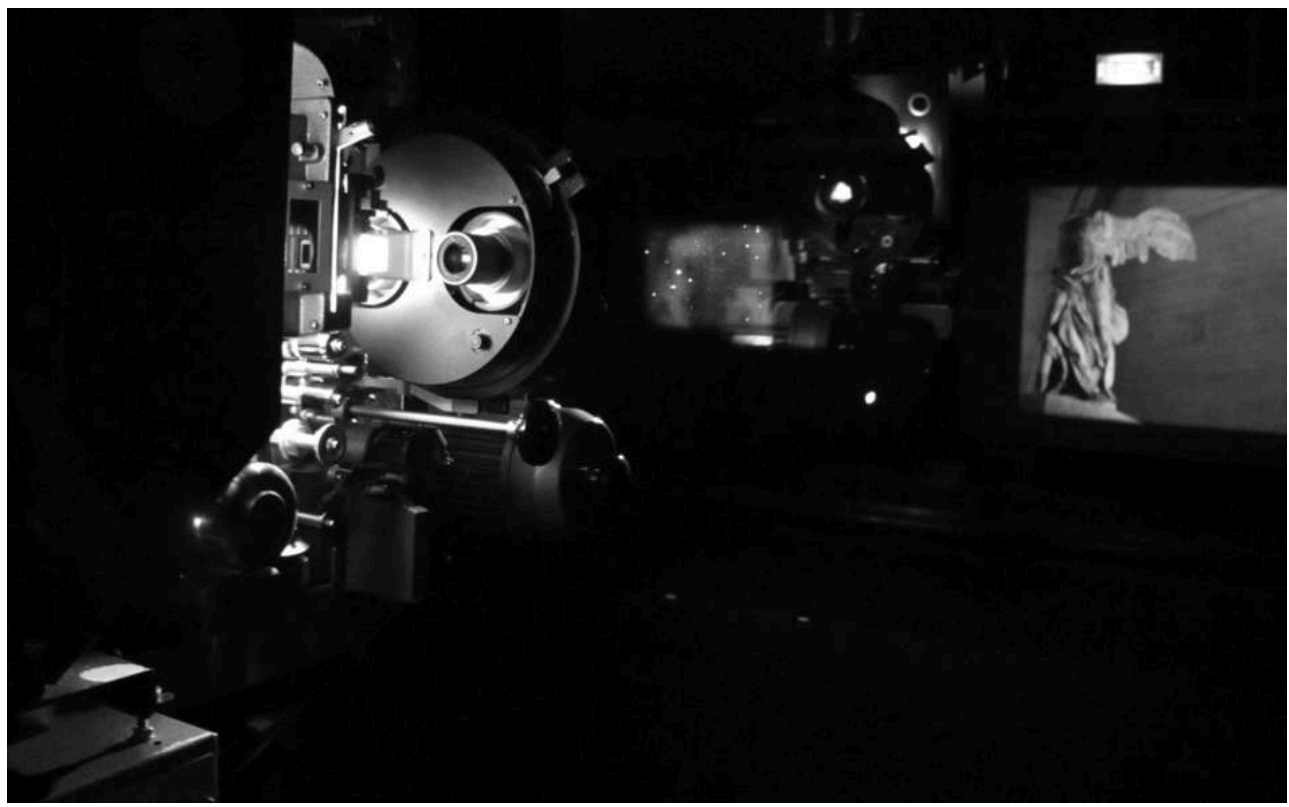

À travers la vitre de la cabine de l'auditorium du Centre Pompidou-Metz, on reconnait une image de Une visite au Louvre, film projeté en $35 \mathrm{~mm}$. C'est le dernier des 32 films de cette rétrospective qui se terminait le 3 avril 2011 par ce film et par une conférence de Pierre-Damien Huyghe.

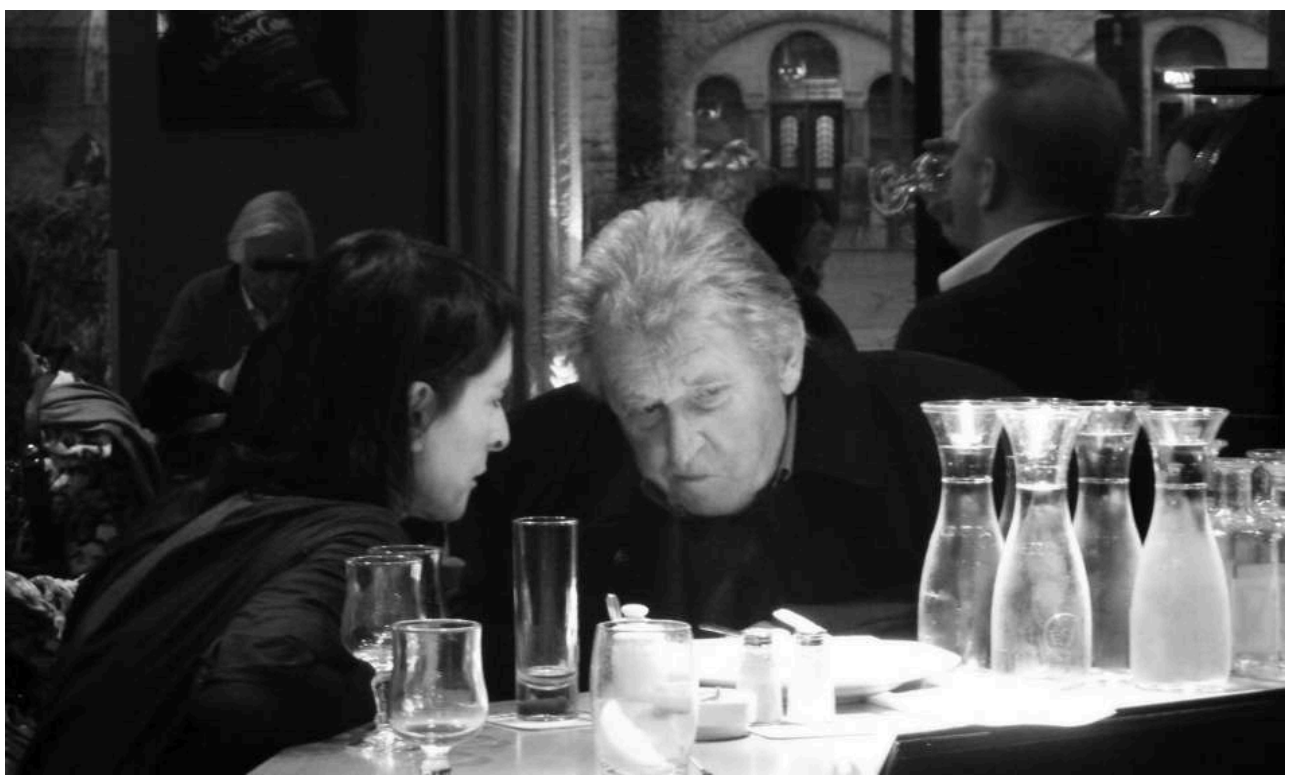

Tout le monde se retrouve à la brasserie l'ABC, en face de la Gare de Metz, pour prendre un dernier verre avec Jean-Marie Straub et le remercier d'être resté à Metz tout le temps de la rétrospective. 


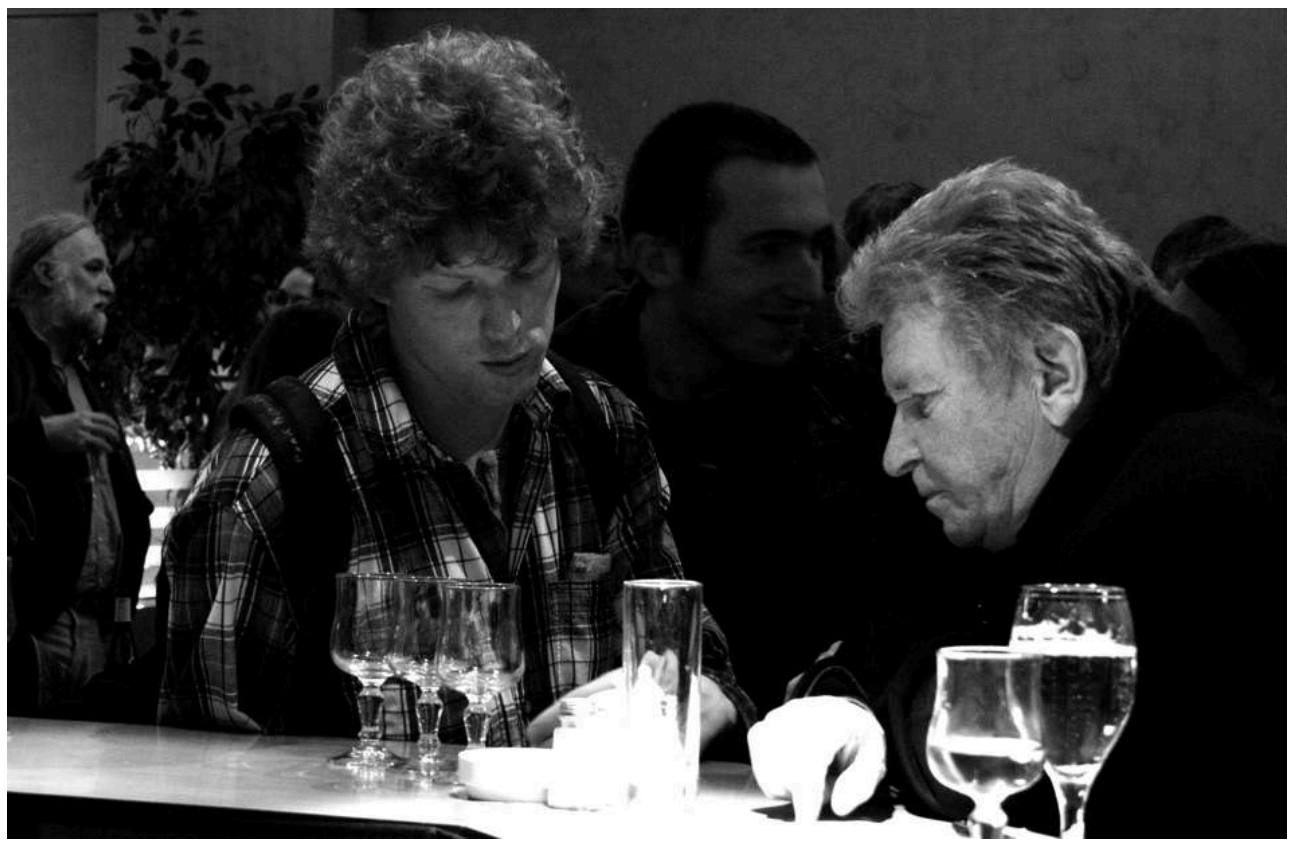

Ici, un étudiant de l'École Supérieure d'Art de Metz poursuit la discussion avec Jean-Marie Straub...

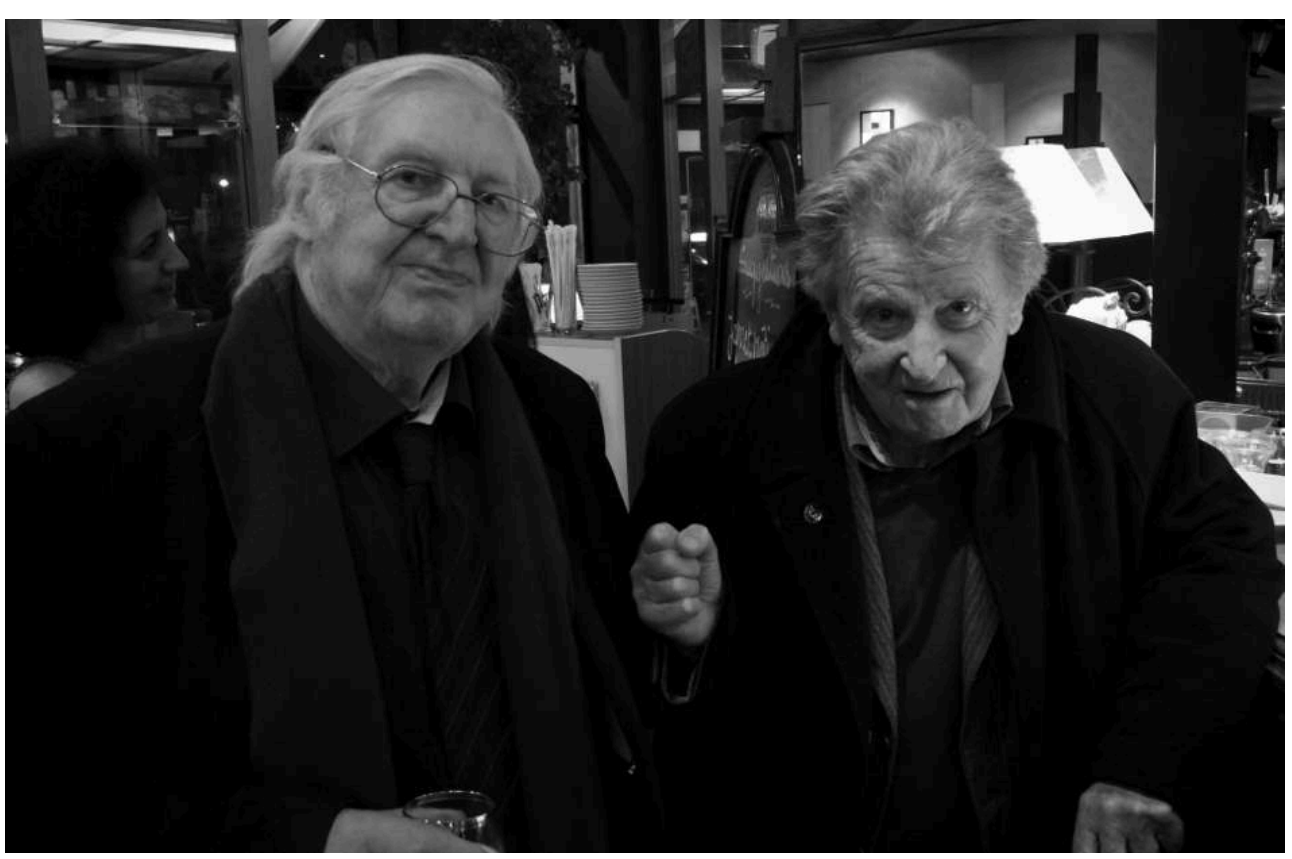

...et là, aux côtés de Jean Goetz, Jean-Marie Straub lève son poing en guise d'au revoir - 3 avril 2011. 